\title{
Integrated process planning, WSPT scheduling and WSLK due-date assignment using genetic algorithms and evolutionary strategies
}

\author{
Halil Ibrahim Demir ${ }^{a *}$, Onur Canpolat ${ }^{a}$ \\ ${ }^{a}$ Department of Industrial Engineering, Sakarya University, Turkey \\ hidemir@sakarya.edu.tr, onurcanpolat@sakarya.edu.tr
}

\section{ARTICLE INFO}

Article history:

Received: 7 November 2016

Accepted: 7 August 2017

Available Online: 2 November 2017

Keywords:

Process planning

Weighted scheduling

Weighted due-date assignment

Genetic algorithm

Random search

AMS Classification 2010:

90-08, 90B35, 78M32, 90C59

\begin{abstract}
Process planning, scheduling and due-date assignment are three important manufacturing functions in our life. They all try to get local optima and there can be an enormous loss in overall performance value if they are handled separately. That is why they should be handled concurrently. Although integrated process planning and scheduling with due date assignment problem is not addressed much in the literature, there are numerous works on integrated process planning and scheduling and many works on scheduling with due date assignment. Most of the works in the literature assign common due date for the jobs waiting and due dates are determined without taking into account of the weights of the customers. Here process planning function is integrated with weighted shortest processing times (WSPT) scheduling and weighted slack (WSLK) due date assignment. In this study unique due dates are given to each customer and important customers get closer due dates. Integration of these three functions is tested for different levels of integration with genetic algorithms, evolutionary strategies, hybrid genetic algorithms, hybrid evolutionary strategies and random search techniques. Best combinations are found as full integration with genetic search and hybrid genetic search. Integration of these three functions provided substantial improvements in global performance.
\end{abstract}

(cc) $\mathrm{EY}$

\section{Introduction}

Traditionally process planning, scheduling and due date assignment are treated sequentially and separately. Independently predetermined process planning, scheduling and due date assignment can cause poor global performance and can be a poor input to the downstream functions. For example, independently predetermined process plans can be poor input to scheduling. Process planners can select same desired machines repeatedly, thus some machines may be starving. In this case, these plans may not be followed at the shop floor level. Independently predetermined scheduling without taking into consideration the due dates, may worsen global performance. As we may unnecessarily increase earliness and tardiness of some jobs. Independently given due dates can be unrealistic for the shop floor. They may be determined either too early or too late in which can worsen the production performance because of unnecessary tardiness, earliness or due dates.

Meanwhile, we should consider the importance of each customer because we may unnecessarily give very close due dates for the unimportant customer and give far due dates for very important customers. This situation may cause poor performance.

If we look at the literature we can find numerous works on integrated process planning and scheduling (IPPS) and scheduling with due date assignment (SWDDA). But if we search for works on integrated process planning, scheduling and due date assignment (IPPSDDA), only a few studies were found in the literature.

Merely scheduling part of the problem already belongs to the class of NP-hard problems, that is why heuristic solutions are required to solve the problem. We cannot find the optimum solution to the problem in a reasonable amount of time when it gets larger. That is why heuristic methods are used to solve this problem. When we integrate three functions, the problem becomes even more complex. For this reason, we applied genetic algorithms, evolutionary strategies and random search in the solution of the integrated

\footnotetext{
*Corresponding author
} 
problem.

As we integrate more functions together overall solution becomes better and to prove this claim we integrated each function step by step. Finally, we integrated weighted shortest processing times (WSPT) scheduling with weighted slack (WSLK) due date assignment and process plan selection. We used WSPT because it is a popular dispatching rule that schedules shorter and important jobs first. Similarly, WSLK is a common due date assignment technique which adds slack to the processing times. In addition, we took into account weight of each job so that close due dates are given for important jobs and scheduled first and far due dates are given for unimportant jobs and scheduled later.

We used genetic algorithms (GA), hybrid genetic algorithms (R-GA), evolutionary strategies (ES), hybrid evolutionary strategies (R-ES), random search (RS) and ordinary solutions (OS) in the solution of the integrated problem. Problem is represented using chromosomes and first two genes are used for due date assignment and dispatching rules respectively. Remaining genes represents the selected route of jobs. Since the problem is NP-Hard, we used pure and hybrid metaheuristics in the solution. We also compared search results with ordinary solutions which are the initial results. We tried to prove the importance of search techniques and inferiority of initial random solutions. We also tried to observe superiority of directed genetic or evolutionary searches over undirected random search. Meanwhile, we tried to observe the power of hybrid searches which use random search initially and turn into directed search at the following iterations.

Let us give definitions of each function one by one; Society of Manufacturing Engineers has defined process planning as the systematic determination of the methods by which a product is to be manufactured economically and competitively. Zhang and Mallur defined production scheduling as a resource allocator, which considers timing information while allocating resources to the tasks [1]. Pinedo and Chao [2] defined scheduling as a proper allocation of resources that enables the company to optimize its objectives and achieve its goal. They also defined the job shopscheduling environment as; $\mathrm{n}$ jobs to be processed on $\mathrm{m}$ machines to process these jobs. Each job processed in predetermined routes, visiting a number of machines. Job shop problems are seen in industries where orders have specified characteristics and order sizes are relatively small. According to Gordon et al. [3] "The scheduling problems involving due dates are of permanent interest. In a traditional production environment, a job is expected to be completed before its due date. In a just-in-time environment, a job is expected to be completed exactly at its due date."

There was a tremendous development in hardware, software and algorithm. With these developments, it became possible to solve problems which could not be solved earlier. After recent developments in computers, it is easier to prepare process plans using Computer Aided Process Planning (CAPP). As we mentioned earlier, these three functions effect each other and upstream decisions effect downstream functions and thus overall performance is affected. Poorly prepared process plans may cause unbalanced machine loading and reduce shop floor efficiency. Sometimes poorly prepared process plans are not followed on the shop floor. Since its easier to prepare process plans using CAPP, we may prepare alternative process plans and we can select among alternatives to balance workload at the shop floor. In case of contingencies such as machine breakdowns we can redirect jobs at the shop floor. This increases shop floor utilization and helps to balance it.

Customers are not equally important so we had better give close due dates to important customers and relatively far due dates to less important customers. The weighted due date assignment is not mentioned in IPPS and SWDDA problems in the literature. Besides assigning closer due dates for important customers we should also schedule important customers earlier as we did in this study. The problem should be solved in a reasonable amount of time, thus some powerful heuristics should be used. GA, R-GA, ES, R-ES and RS metaheuristics are utilized in this study.

After representing the problem as a chromosome we gave a higher probability of selection for dominant genes which are due date assignment and dispatching genes. Because these genes greatly affect the performance measure compared to any job route.

In the literature some works tried to minimize tardiness, some tried to minimize tardiness and earliness, some minimized maximum absolute lateness, and some minimized number of tardy jobs. Unlike these works, we tried to minimize the sum of weighted tardiness, earliness and due date related costs in this study.

Customers do not want long due dates, and far due dates can cause customer losses or price discounts and increase production costs. That is why we did not want to give far due dates unnecessarily, especially for the important customers. Conventionally tardiness is not desired. On the other hand in just-in-time (JIT) environment earliness is also undesired. Earliness means stock holding, spoilage, and some other earliness related costs. Tardiness means loss of customer goodwill, loss of customer permanently or may be a discount on the price. Thus we did not want any of these costs at our performance measure. Of course, we penalized these cost terms according to the weight of each job.

In this study, we did not want to give far due dates unnecessarily especially for important customers. We also wanted to give reasonable due dates so that we can keep our promises and reduce tardiness and earliness. We wanted jobs to be completed as close as possible to given reasonable due dates and tardiness is penalized more compared to earliness. 


\section{Literature survey}

There are numerous works on IPPS and SWDDA or SWDWA problems in the literature. But there are only a few works on IPPSDDA problem. Demir and Taskin [4] worked on this problem for a Ph.D. thesis. Later Ceven and Demir [5] studied the benefit of integrating due date assignment with IPPS problem in a Master of Science thesis. Later Demir et al. [6] worked on the integration of process planning and due date assignment with ATC (Apparent Tardiness Cost) dispatching. Demir et al. [7] studied the integration of process planning and scheduling with SLK (Slack) due date assignment. In these studies unique due dates are determined for every customer.

Job shop scheduling with alternative process plans is integrated with due date determination. Concerning this research, we integrated WSPT dispatching with WSLK due date determination where alternative process plans are possible. As a distinct approach weighted SLK due date assignment method is used where weights of each customer are taken into account while determining unique due dates for each customer in this study. Important customers are given relatively closer due dates contrary to the relatively less important customers.

If we look at SWDDA problems we see that most of the works are done on common due date assignment. Parts of a product which are waiting to be assembled should be ready at the same time. But in this study, as mentioned above each customer has its own due dates.

Since job shop scheduling belongs to the NP-hard problem class, integrated problems are even harder to solve. For example, if we look at IPPS problems, exact solutions are only possible for very small problems. That is why genetic algorithms and its variants are more applicable for job shop scheduling problems or IPPS problems as they are utilized in this study. Zhu [8] and Wang and $\mathrm{Li}$ [9] used genetic algorithms and its variants in job shop scheduling.

"If we look at the literature we see that its hard to solve integrated problems. Some solutions are only possible for small problems. For IPPS in the literature, people use genetic algorithms, evolutionary algorithms or agent-based approach for integration, or they decompose problems because of the complexity of the problem. They decompose problems into loading and scheduling subproblems. They use mixed integer programming at the loading part and heuristics at the scheduling part" Demir et al. [7].

If we look at the early works on IPPS problem, we can see the following literature on this problem; Nasr and Elsayed [10], Hutchinson et al. [11], Chen and Khoshnevis [12], Zhang and Mallur [1], Brandimarte [13], Morad and Zalzala [14]. After these studies more works are done on IPPS such as: Ming and Mak [15], Tan and Khoshnevis [16], Kim et al. [17], Kumar and Rajotia [18], Lim and Zhang [19], Tan and Khoshnevis [20], Kumar and Rajotia [21], Moon et al. [22], Guo et al. [23], Leung et al. [24], Phanden et al. [25], Petrovic et al. [26], Zhang et al. [27], and Zhang and Wong [28].

Scheduling with due date assignment is also popular research topic which is extensively studied in the literature. Gordon et al. [3] presented a good literature survey and it will be useful to see this work before studying SWDDA problem. When we look at works on this problem most of them assigned unweighted due dates.

In this study, weighted due dates are assigned. Relatively important customers get closer due dates which greatly improve performance measure. At the IPPS and SWDDA problem some works penalize tardiness, some of them punish number of tardy jobs and some penalize both earliness and tardiness. In this study, we penalized all of the weighted due dates, weighted tardiness and weighted earliness cost. We give relatively close due dates for important customers and use WSLK as due date assignment and we schedule important customers first and used WSPT dispatching rule, so we save a lot from weighted due date related costs, weighted tardiness and earliness costs.

In the literature, we can observe works in two groups according to the number of machines. Single machine scheduling with due date assignment (SMSWDDA) and Multi-machine scheduling with due date assignment (MMSWDDA). Many works are on single machine problem and many of them on the multimachine problem. At the former case, jobs are tried to be scheduled before a single machine and better due dates are tried to be found. At the latter case, jobs are tried to be scheduled on multiple machines and tried to be assigned better due dates. In our study, we have $n$ jobs to be scheduled on $\mathrm{m}$ machines and each job will be given a unique due date according to processing time, the importance of the customer and given slack.

If we list some literature on SMSWDDA problem we can find following works; Panwalkar [29], Biskup and Jahnke [30], Cheng et al. [31], Cheng et al. [32], Lin et al. [33], Ying [34], Xia et al. [35], Gordon and Strusevich [36], and Li et al. [37].

When we list researchers on MMSWDDA problem we can give following works on this problem; Adamopolous and Pappis [38], Cheng and Kovalyov [39], Birman and Mosheiov[40] and Lauff and Werner [41]. Additionally following works can be given for SWDDA problem; Allaoua and Osmane [42], Yang et al. [43], Tuong and Soukhal [44], Li et al. [45], Li et al. [37], Vinod and Sridharan [46], Li et al. [47], Zhang and $\mathrm{Wu}$ [48], Yin et al. [49], Iranpoor et al. [50] Yin et al. [51], Shabtay [52], and Koulamas [53].

If we look at recent works we can see numerous works on scheduling with due window assignment (SWDWA) instead of SWDDA. In this studies, due windows are tried to be determined instead of a single point due date. The objective is to find better due windows with better starting point in time and length of windows. Jobs completed within due windows cause no cost and jobs completed out of windows cause tardiness or earliness 
costs. We can list works on this problem as; Mosheiov and Sarig [54], Cheng et al. [55], Zhao and Tang [56], Janiak et al. [57], Wang et al. [58], Ji et al. [59], Ji et al. [60] Yang et al. [61] and Liu et al. [62].

\section{Problem studied}

We studied IPPSDDA problem with different levels of integration. Alternative process plans, WSPT and service in random order (SIRO) dispatching rules and WSLK and Random (RDM) due date assignment rules are handled concurrently.

Four shop floors are studied. There are five alternative routes in relatively small shop floors. However, there are three alternative routes in relatively large shop floors. Because number of routes increases complexity and it takes more time to solve the problem. The number of alternative routes is limited to three in order to find a good solution in a reasonable amount of time.

Initially, SIRO dispatching rule and RDM due date assignment rule are used to represent unintegrated combination of the problem. RDM due date assignment is used to represent external due date assignment. WSLK is used to represent internal due date assignment. At the previous case, we try to optimize performance measure in case of given external due date. But at the second case, we assign due dates internally and we try to find best due dates which are the most suitable for us and optimize performance measure.

After unintegrated combination, we integrated WSPT scheduling with process plan selection. Here, due date assignment is still unintegrated and randomly determined. Later we tested the combination where due date assignment is integrated with process plan selection but here scheduling is unintegrated and jobs are scheduled according to SIRO. Finally, we integrated three functions and tested fully integrated combination.

As it is mentioned earlier, we have four shop floors. For example, at the smallest shop floor, we have 25 jobs and 5 machines. Each job has 5 alternative routes and there are 10 operations at each route. At the largest shop floor, there are 175 jobs and 35 machines. Each job has 3 alternative routes with 10 operations each. Processing times are determined as $\left[\left(12+\mathrm{z}^{*} 6\right)\right]$ randomly. Here $\mathrm{z}$ is standard normal numbers and practically processing time of each operation changes in between 1 and 30 minutes.

Operations are assigned to machines randomly in each shop floor. Characteristics of each shop floor are as given in Table 1.

In this study, we assumed that shop floor works one shift that is 8 hours per day. So a shift makes $8 * 60=480$ minutes. As a performance measure, we assumed sum of weighted tardiness, earliness and due dates. All terms are punished linearly according to weights of customers. We also assumed fixed cost if there is tardiness or earliness.
Table 1. Shop floors.

\begin{tabular}{|c|c|c|c|c|}
\hline Shon floor & SF1 & SF2 & SF3 & SF4 \\
\hline snop noor & $25 \times 5 \times 5$ & $75 \times 15 \times 5$ & $125 \times 25 \times 3$ & $3175 \times 35 \times 3$ \\
\hline \# of machines & 5 & 15 & 25 & 35 \\
\hline \# of Jobs & 25 & 75 & 125 & 175 \\
\hline \# of Routes & 5 & 5 & 3 & 3 \\
\hline $\begin{array}{l}\text { Processing } \\
\text { Times }\end{array}$ & \multicolumn{4}{|c|}{$\lfloor(12+z * 6)\rfloor$} \\
\hline \# of op. per job & \multicolumn{4}{|c|}{10} \\
\hline
\end{tabular}

Due dates are punished proportionally to the weight of the job and length of the due date. Due date length is multiplied with 8 . Earliness is punished with 5 unit fixed cost and proportionally with multiplier 4 and multiplied with the weight of job. Tardiness is punished more compared to other terms. Because it is the most undesired component. Tardiness is punished with 10 unit fixed cost and proportionally with multiplier 12 and finally multiplied with the weight of job.

Punishment functions are given below where D is used for the due date of job $\mathrm{j}, \mathrm{E}$ is used for earliness of job $\mathrm{j}$ and $\mathrm{T}$ is used for the tardiness of job j. PD is the penalty of due-date of job j, PE is the penalty of earliness and PT is the penalty of the tardiness of job j. Penalty (j) is the total penalty of job $\mathrm{j}$ and total penalty is the ultimate value that we want, which shows total punishment for all of the jobs;

$$
\begin{gathered}
\text { PD }(j)=\text { weight }(j) * 8 *\left(\frac{D}{480}\right) \\
\text { PE }(j)=\text { weight }(j) *\left(5+4 *\left(\frac{E}{480}\right)\right) \\
\text { PT }(j)=\text { weight }(j) *\left(10+12 *\left(\frac{T}{480}\right)\right) \\
\text { Penalty }(j)=\operatorname{PD}(j)+\operatorname{PE}(j)+\operatorname{PT}(j) \\
\text { Total Penalty }=\sum_{j} \text { Penalty }(j)
\end{gathered}
$$

\section{Used techniques}

We used five search techniques in this study. These techniques are GA, R-GA, ES, R-ES and RS. Results of searches are compared with OS and RS results to find out the power of directed and hybrid searches over undirected (random) search and over OS results. Solution techniques are explained as follows:

Genetic Algorithm (GA): One of the most powerful search technique in this study was genetic search. For each shop floor, we applied given number of genetic iterations. Two genetic operators which are crossover and mutation are used in genetic iterations. There are three populations used in this study. First is the main population, second is used for crossover population and the last is used as mutation population. We have 10 chromosomes in the main population and we produce 8 chromosomes using previous main population by using crossover operator for crossover population. Again by 
using previous main population we produce 5 more chromosomes by using mutation operator to get mutation population. According to the literature, the crossover is expected to be more powerful compared to the mutation operator. But as number of pairs of chromosomes selected for crossover and number of chromosomes selected for mutation increase, the time required to solve the problem also increases. On the one hand selecting chromosomes with better performance for crossover and mutation operators with higher probability improves the performance measure better and on the other hand, marginal improvement in selecting chromosomes with worse performance is poor compared the former case. So it is better to apply crossover with a higher rate and select better chromosomes with higher probability and not to select all of the chromosomes to reduce the time required to solve the problem. That's why we selected four pairs of chromosomes for crossover and selected five chromosomes for mutation. Using three populations which are previous main population, new crossover population and new mutation population we determine next main population and this makes one genetic iteration. Out of 23 chromosomes from three populations, we select best 10 chromosomes for next step main population. This search is also called directed search since updated best population is used to determine next step main population at every iteration.

Evolutionary Strategies (ES): In Germany, two students of Technical University of Berlin developed ES, while solving their optimization problem [63], [64]. Unlike GA, ES uses only mutation operator. To be fair in comparison in GA, R-GA, ES, R-ES and RS we use the same number of iterations and at every iteration, we produce 13 new solutions and we use same amount of new solutions.

Random Search (RS): We produce 13 brand new solutions in every iteration. To be fair amongst methods, we used the same number of iterations and the same amount of chromosomes at each iteration in all searches.

Hybrid Genetic Algorithms (R-GA): Initially random iterations are applied. Later iterations are turned into genetic iterations. It is very useful to apply random search in the beginning since it scans solution space faster and better. Afterwards, it becomes very poor to continue with random search and at this point, it is better to use a powerful directed search technique. For instance, if we produce a random number between 1 and 1000, the expected value becomes 500 where the marginal gain is 500 . On the other hand, if we produce two random numbers and take their maximum then expected value of this maximum is 667 so marginal gain sharply reduced to 167 . Furthermore, if we produce three random numbers and take the maximum of these three numbers then expected value becomes 750 and marginal gain further reduced 83 . If we sort marginal gains in descending order; 500, 167, 83 are the marginal benefits of initial random iterations, respectively. So as its explained above initial random iterations are very useful but later it becomes drastically poor to apply.

Hybrid Evolutionary Strategies (R-ES): Initially random iterations are applied and later iterations are turned into evolutionary iterations in this search.

Iterations parameters for all search techniques are summarized in Table 4.

Ordinary Solution (OS): For every shop floor, we used only randomly produced chromosomes in the beginning as OS to represent how poor an ordinary solution can be.

CPU times required for pure and hybrid metaheuristics are given in Section 6.

If $n$ is the number of jobs then we have $n+2$ genes at each chromosome. The first gene represents due date assignment methods and second gene is used for dispatching rules. Remaining genes are used to represent selected route of each job. In the relatively small shop floors, jobs can have 1 route out of 5 alternatives and at the relatively large shop floors, jobs have 3 alternative routes. A sample chromosome is given in Figure 1.

One thing we applied in this study is dominant genes. First and second genes affect results much more compared to other genes which are the route of jobs. For this reason, while applying GA, R-GA, ES, R-ES and RS first two genes are selected with a higher probability of crossover or mutation in GA and ES using dominant genes with higher probability improved efficiency of the solution techniques.

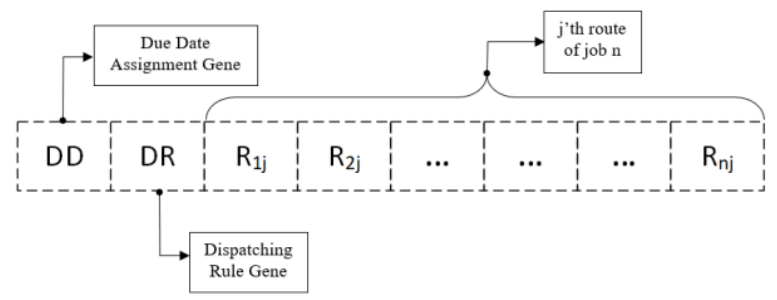

Figure 1. Sample chromosome.

Due dates are assigned using mainly two different type of rules. The first rule is weighted due date assignment rule WSLK which represents internal due date assignment and considers weights of each customer while assigning due dates. The second rule is RDM due date assignment rule that assigns due dates randomly which represents external due date assignment. With the constants used first gene takes one of four values. These rules are explained below in Table 2 and in Appendix A.

Table 2. Due-date assignment rules.

\begin{tabular}{ccc}
\hline Method & Constant $\mathrm{q}_{\mathrm{x}}$ & Rule no: \\
\hline WSLK & $\mathrm{q}_{\mathrm{x}}=\mathrm{q}_{1}, \mathrm{q}_{2}, \mathrm{q}_{3}$ & $1,2,3$ \\
RDM & & 4 \\
\hline
\end{tabular}

Two different methods were used in order to dispatch. One is WSPT dispatching which schedules jobs according to the weights of the customers and processing times of the jobs. The other rule is SIRO 
which schedules jobs in random order. Dispatching rules are given and explained in Table 3 and in Appendix B.

Table 3. Dispatching rules.

\begin{tabular}{cc}
\hline Method & Rule no \\
\hline WSPT & 1 \\
SIRO & 2 \\
\hline
\end{tabular}

Table 4. Iteration numbers for pure and hybrid searches.

\begin{tabular}{cccccccc}
\hline & \multirow{4}{*}{ ES } & \multicolumn{2}{c}{ R-ES } & \multirow{2}{*}{ RS } & GA & \multicolumn{2}{c}{$\begin{array}{c}\text { R-GA } \\
\text { Hybrid }\end{array}$} \\
\hline $\begin{array}{c}\text { Shop } \\
\text { Floor Iter\# }\end{array}$ & ES & Random & ES & Random & GA Random GA \\
\hline 1 & 200 & 20 & 180 & 200 & 200 & 20 & 180 \\
2 & 150 & 15 & 135 & 150 & 150 & 15 & 135 \\
3 & 100 & 10 & 90 & 100 & 100 & 10 & 90 \\
4 & 50 & 5 & 45 & 50 & 50 & 5 & 45 \\
\hline
\end{tabular}

\section{Solutions compared}

SIRO-RDM (OS, RS, ES, R-ES, GA, R-GA): This is an unintegrated combination of the problem. Jobs are scheduled in random order and due dates are determined randomly. Random due date assignment represents exogenous due dates where we have no control over it.

WSPT-RDM (OS, RS, ES, R-ES, GA, R-GA): In this combination, a powerful dispatching rule WSPT is integrated with process planning, but due dates are still determined randomly. Here substantial improvement is obtained.

SIRO-WSLK (OS, RS, ES, R-ES, GA, R-GA): In this combination, this time WSLK due date assignment is integrated with process plan selection but this time dispatching is made in random order. Although this integration provides substantial improvement, unfortunately, SIRO dispatching sharply deteriorates the performance measure.

WSPT-WSLK (OS, RS, ES, R-ES, GA, R-GA): With this combination, we integrated process plan selection, scheduling and due-date assignment by using WSPT dispatching and WSLK due date assignment rules. This is the highest integration level.

All twenty-four solutions mentioned above are compared with one another. Different level of integrations are tested and searches are compared with each other and with ordinary solutions. Higher integration levels are found better and best results are obtained where three functions are integrated. Results are presented in Section 6 experiments and results section and conclusions are made in the final section.

\section{Experiments and results}

We coded the problem using $\mathrm{C}++$ syntax. This program can perform genetic, evolutionary or random iterations while searching for better solutions, assign due dates and schedule jobs and evaluate performance measure for every given solution. At the first gene of the chromosomes, two rules which are WSLK and RDM rules are used and with the different constants used the first gene can take one of four values. At the second gene, two dispatching rules which are WSPT and SIRO rules are used. This gene can take one of two values. Remaining genes take values according to the selected route among given alternatives.

We ran the program using a laptop with $2.4 \mathrm{GHz}$ processor with Intel i7 processor and 16 GB Ram with Borland $\mathrm{C}++5.02$ compiler.

CPU times of the problems are given in Table 5. Since searches take time, CPU times for searches are given except ordinary solutions which require a negligible amount of time.

For different shop floors, given number of iterations are applied. At GA we applied genetic iterations which uses crossover and mutation operators. At the ES we applied only mutation operator. Since these are directed searches we use updated best solutions to generate new generations. On the other hand, RS is undirected search and we produce brand new random solutions at every iteration. We apply 200, 150, 100 and 50 iterations for each of the shop floors respectively.

If we look at Table 5 for shop floor 1 , iterations took around 20 seconds approximately. For the second shop floor, it took approximately 200 seconds. At the third shop floor, it took in between 200 and 300 seconds. Finally, for the largest shop floor, 50 iterations took approximately 300 seconds.

First of all, we tested unintegrated solutions and we tested SIRO-RDM combination. Later, we integrated WSPT rule with process plan selection and we tested WSPT-RDM combinations. After that, we tested integration of WSLK rule with process planning. We tested SIRO-WSLK combinations. Finally, we integrated all three functions and this is the full integration and we tested WSPT-WSLK combinations. These solutions are explained in Section 5.

Four shop floors are tested for mentioned twenty-four types of solutions. For smallest shop floor we applied 200 genetic, evolutionary or random iterations. Iteration parameters can be found in Table 4. CPU times required to solve the shop floors for each search technique is given in Table 5. Smallest shop floor results are tabulated in Table 5 and illustrated in Figure 2. Results show that searches are found very useful and directed search outperformed undirected search. Furthermore higher integration is found better and fully integrated combinations are found the best. R-GA method gave the best result.

Similar results are obtained for the second shop floor. At this shop floor, we applied 150 genetic, evolutionary or random iterations and CPU times are given in Table 5. Results are listed in Table 5 and illustrated in Figure 3. Integrating functions are found to be useful. As integration level increases solutions become better and highest integration level with genetic search gave the best results. Directed searches outperformed undirected 
Integrated process planning, WSPT scheduling and WSLK due-date assignment using genetic algorithms... 79 search.

Table 5. Comparison of twenty-four solutions for each shop floor.

\begin{tabular}{|c|c|c|c|c|c|c|c|c|c|c|c|c|c|c|c|c|c|}
\hline \multirow{2}{*}{$\begin{array}{c}\text { Level of } \\
\text { Integration } \\
\text { (Combination) } \\
\end{array}$} & \multirow{2}{*}{ Method } & \multicolumn{4}{|c|}{ Shop Floor 1} & \multicolumn{4}{|c|}{ Shop Floor 2} & \multicolumn{4}{|c|}{ Shop Floor 3} & \multicolumn{4}{|c|}{ Shop Floor 4} \\
\hline & & Best & Avg & Wor: & Cr & Best & & Worst & $\mathrm{CP}$ & Best & A & Worst & $\mathrm{CP}$ & Best & Av & Wc & CPU \\
\hline \multirow{6}{*}{ SIRO-RDM } & OS & 293 & 293 & 293 & 0 & 906 & 906 & 906 & 0 & 1413 & 1413 & 1413 & 0 & 2020 & 2020 & 2020 & 0 \\
\hline & ES & 256 & 260 & 263 & 19 & 826 & 838 & 844 & 217 & 1315 & 1323 & 1329 & 277 & 1860 & 1871 & 1879 & 295 \\
\hline & R-ES & 248 & 252 & 255 & 20 & 827 & 835 & 839 & 216 & 1322 & 1325 & 1327 & 277 & 1861 & 1875 & 1885 & 298 \\
\hline & GA & 248 & 251 & 253 & 19 & 841 & 847 & 849 & 217 & 1309 & 1319 & 1323 & 274 & 1833 & 1872 & 1879 & 297 \\
\hline & R-GA & 254 & 257 & 259 & 19 & 823 & 831 & 833 & 217 & 1303 & 1309 & 1314 & 274 & 1871 & 1882 & 1890 & 298 \\
\hline & $\mathrm{RS}$ & 268 & 273 & 275 & 19 & 853 & 864 & 870 & 222 & 1355 & 1372 & 1378 & 286 & 1908 & 1925 & 1934 & 303 \\
\hline \multirow{6}{*}{ WSPT-RDM } & OS & 231 & 231 & 231 & 0 & 730 & 730 & 730 & 0 & 1153 & 1153 & 1153 & 0 & 1691 & 1691 & 1691 & 0 \\
\hline & ES & 210 & 212 & 212 & 40 & 666 & 672 & 673 & 212 & 1084 & 1089 & 1092 & 274 & 1554 & 1560 & 1563 & 293 \\
\hline & R-ES & 211 & 212 & 212 & 34 & 675 & 679 & 682 & 215 & 1086 & 1094 & 1096 & 275 & 1560 & 1567 & 1572 & 299 \\
\hline & GA & 213 & 213 & 214 & 21 & 678 & 679 & 679 & 207 & 1101 & 1102 & 1103 & 274 & 1564 & 1564 & 1564 & 299 \\
\hline & R-GA & 208 & 209 & 209 & 20 & 686 & 687 & 687 & 206 & 1102 & 1104 & 1106 & 271 & 1542 & 1543 & 1544 & 298 \\
\hline & $\mathrm{RS}$ & 218 & 221 & 222 & 21 & 701 & 707 & 710 & 215 & 1124 & 1133 & 1140 & 284 & 1589 & 1600 & 1606 & 314 \\
\hline \multirow{6}{*}{ SIRO-WSLK } & OS & 322 & 322 & 322 & 0 & 982 & 982 & 982 & 0 & 1467 & 1467 & 1467 & 0 & 2104 & 2104 & 2104 & 0 \\
\hline & ES & 256 & 271 & 275 & 23 & 853 & 858 & 862 & 230 & 1260 & 1267 & 1272 & 288 & 1770 & 1794 & 1807 & 305 \\
\hline & R-ES & 258 & 265 & 268 & 24 & 851 & 860 & 866 & 229 & 1249 & 1269 & 1275 & 291 & 1785 & 1807 & 1821 & 303 \\
\hline & GA & 260 & 264 & 267 & 23 & 845 & 850 & 854 & 226 & 1222 & 1252 & 1262 & 307 & 1770 & 1783 & 1792 & 302 \\
\hline & R-GA & 255 & 266 & 269 & 22 & 846 & 853 & 857 & 225 & 1255 & 1264 & 1270 & 295 & 1782 & 1789 & 1795 & 305 \\
\hline & RS & 267 & 279 & 283 & 22 & 868 & 884 & 890 & 230 & 1284 & 1294 & 1304 & 311 & 1790 & 1812 & 1825 & 307 \\
\hline \multirow{6}{*}{ WSPT-WSLK } & OS & 247 & 247 & 247 & 0 & 766 & 766 & 766 & 0 & 1120 & 1120 & 1120 & 0 & 1621 & 1621 & 1621 & 0 \\
\hline & ES & 189 & 191 & 192 & 22 & 604 & 617 & 620 & 219 & 931 & 933 & 935 & 233 & 1363 & 1368 & 1373 & 306 \\
\hline & R-ES & 189 & 192 & 193 & 22 & 621 & 626 & 630 & 231 & 937 & 942 & 945 & 228 & 1360 & 1371 & 1377 & 310 \\
\hline & GA & 192 & 193 & 194 & 22 & 601 & 603 & 605 & 213 & 926 & 928 & 930 & 228 & 1351 & 1356 & 1359 & 308 \\
\hline & R-G & 187 & 191 & 193 & 22 & 619 & 621 & 622 & 219 & 931 & 932 & 933 & 235 & 1347 & 1350 & 1353 & 308 \\
\hline & RS & 199 & 202 & 204 & 22 & 629 & 641 & 649 & 224 & 954 & 966 & 972 & 313 & 1379 & 1388 & 1392 & 309 \\
\hline
\end{tabular}

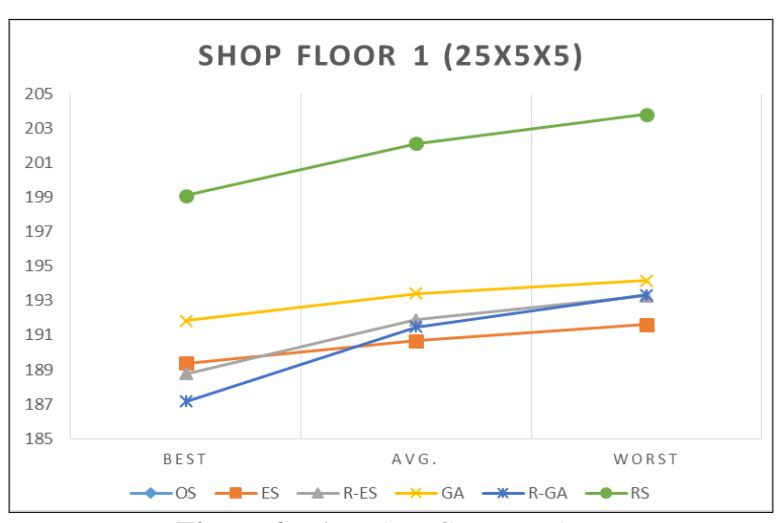

Figure 2. First shop floor results.

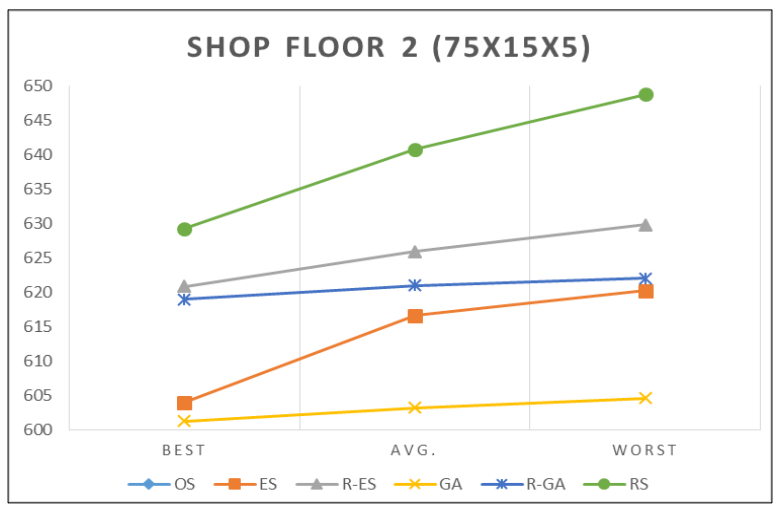

Figure 3. Second shop floor results.

At the third shop floor, GA gave the best result. At this shop floor, we applied 100 iterations and results are summarized in Table 5 and in Figure 4. Directed searches outperformed undirected search.

Last shop floor was the biggest shop floor. We applied

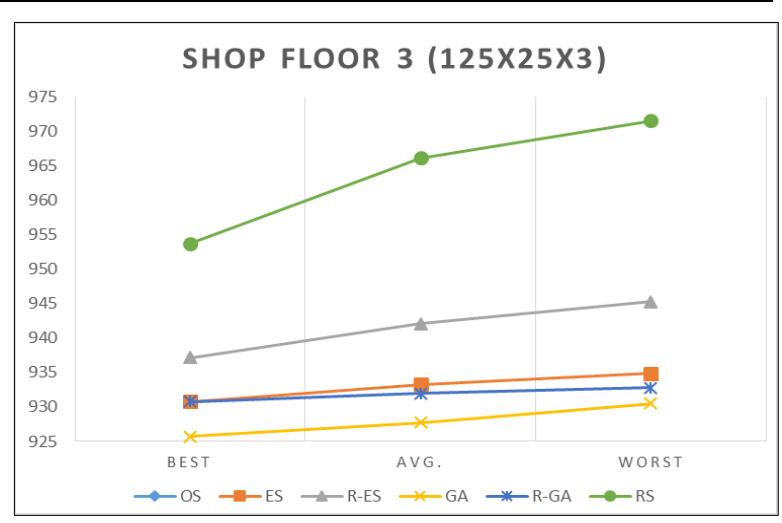

Figure 4. Third shop floor results.

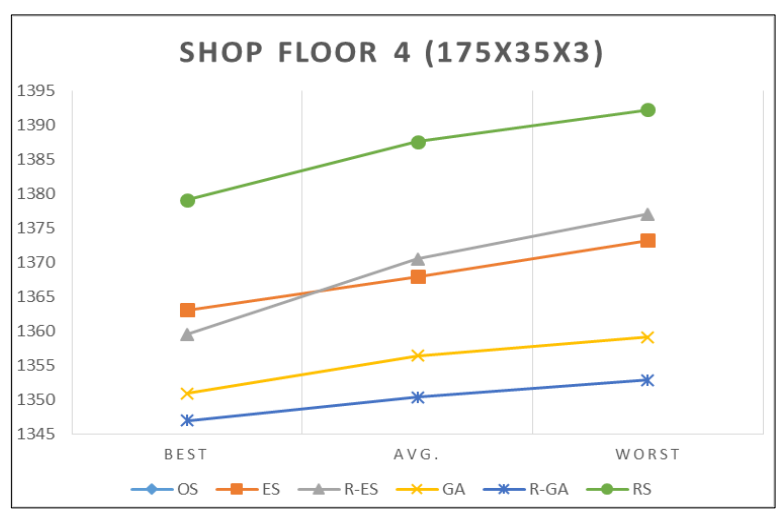

Figure 5. Fourth shop floor results.

50 iterations to find a good solution in a reasonable amount of time. According to the results listed in Table 5 and illustrated in Figure 5, highest integration level with R-GA is found best. According to the results, higher integration level gave better solutions. R-GA 
outperformed all other searches.

If we consider all level of integrations and compare 24 combinations for each shop floor then there are 16 best results. 8 of these best results are obtained through GA and 7 of them is obtained through R-GA search and once we obtained the best result by using ES search. These results can be seen in Table 5 .

\section{Discussions and conclusion}

In this study, we tested different integration level of process planning, weighted scheduling and weighted due date assignment. We used WSPT rule for weighted scheduling as it is a powerful dispatching rule. We applied WSLK rule as due date assignment rule. We considered weights of the jobs because they provide substantial improvements in the performance measure which is the sum of weighted tardiness, earliness and due date related costs. We tested different search techniques which are GA, R-GA, ES, R-ES and RS. We compared search techniques with each other and with OS results for different level of integrations.

In the beginning of the study, we tested unintegrated solutions and we solved the problem according to SIRO-RDM combinations. Later we integrated WSPT scheduling with process plan selection but due dates are still determined randomly. We solved the problem for WSPT-RDM combinations at this level. After that, we integrated WSLK due date assignment with process plan selection. Scheduling is performed in random order and we used SIRO dispatching rule. We tested here SIRO-WSLK combinations. Although WSLK due-date assignment is very useful, SIRO dispatching severely deteriorates the performance measure, that is why this is not as good as other integration levels. At the end, we integrated three functions which are process planning, scheduling and due date assignment. We used WSLK due date assignment rule at the first gene of the chromosomes and used WSPT dispatching rule at the second gene of the chromosomes and tried to find better routes at the remaining genes of the chromosomes. We used dominant genes at the chromosomes because first two genes are much more important compared to the routes of each job. We tested here WSPT-WSLK combinations. Full integration with GA and R-GA techniques are found the best in these four shop floors. Again full integration is always found better compared to the intermediate levels. GA and R-GA searches outperformed other searches and directed searches are always performed better compared to the undirected search. While GA search gave the best results for eight times, compared to R-GA search which gave the best solutions for seven times. ES search gave the best solution only once among all other search techniques.

As a conclusion, we can see that integration level is very important and highest integration level gives the best results. According to the results, we can also say that weighted scheduling and weighted due date assignment also improves global performance which is the sum of weighted tardiness, earliness and due date costs.

Traditionally three functions that we integrated are performed separately which leads to poor global performance and greatly affects the performance measure. In this competitive environment, we should utilize every way that makes us more competitive, reduces our costs and increases our profits. The performance measure is greatly reduced by higher integration level, with weighted scheduling, weighted due date assignment and with a better search technique.

If these three functions are performed sequentially, they give poor inputs for other functions. For example, independently prepared process plans can be poor input for scheduling and can cause unbalanced machine loads and can reduce shop floor performance. Furthermore, these plans may not be followed at the shop floor level at all as they are not realistic. Independently prepared scheduling without considering due dates may cause much more cost at performance measure. Independently given due dates can cause worse performance measure and poorly given due dates makes it harder to keep our promises.

To sum up, this study has shown that higher integration gives better performance measure and we should use highest integration level. WSPT is a strong dispatching rule that takes into account of weights of each customer, and WSLK is a strong due date assignment rule that considers the importance of each customer. Alternative process plans help us to improve scheduling and due date assignment performance so we get much better global performance. Thus it is very useful to implement WSLK rule while assigning due dates and we should give closer due dates for more important customers and relatively far due dates for relatively less important customers. We should also schedule jobs that have both shorter processing times and belong to important customers earlier than the other jobs.

In terms of solution techniques, directed searches are always better than undirected search. GA and R-GA techniques were found best and hybrid techniques are found promising.

\section{Appendix A: Due-date assignment rules}

WSLK (Weighted Slack) $\rightarrow$ Due $=$ TPT $+\mathrm{q}_{\mathrm{x}} * \mathrm{k}$ (According to weights) $\mathrm{q}_{\mathrm{x}}=\mathrm{q} 1, \mathrm{q} 2$ or $\mathrm{q} 3$

$\mathrm{q} 1=0.5 * \mathrm{Pav}, \mathrm{q} 2=\mathrm{Pav}, \mathrm{q} 3=1.5 * \mathrm{Pav}$

RDM (Random due-date assignment) $\rightarrow$ Due $=\mathrm{N} \sim$ $\left(3 * \mathrm{P}_{\mathrm{av}},\left(\mathrm{P}_{\mathrm{avg}}\right)^{2}\right)$

TPT: Total processing time

$\mathbf{P}_{\mathbf{a v g}}$ : Mean processing time of all job waiting

\section{Appendix B: Dispatching rules}

WSPT: Weighted shortest processing time first

SIRO (Service in Random order): A job among waiting jobs is selected randomly to be processed. 


\section{References}

[1] Zhang, H.C., \& Mallur, S. (1994). An integrated model of process planning and production scheduling. International Journal of Computer Integrated Manufacturing, 7, 356-364.

[2] Pinedo, M. and Chao, X. (1999). Operations scheduling with applications in manufacturing and services. McGraw-Hill Companies.

[3] Gordon, V., Proth, J.M., \& Chu, C. (2002). A survey of the state-of-the-art of common due date assignment and scheduling research. European Journal of Operational Research, 139, 1-25.

[4] Demir, H.I. and Taskin, H. (2005). Integrated Process Planning, Scheduling and Due-Date Assignment. $\mathrm{PhD}$ Thesis.

[5] Ceven, E. and Demir, H.I. (2007). Benefits of Integrating Due-Date Assignment with Process Planning and Scheduling. Master of Science Thesis.

[6] Demir, H.I., Cakar, T., Ipek, M., Uygun, O., \& Sari, M. (2015). Process Planning and Due-date Assignment with ATC Dispatching where Earliness, Tardiness and Due-dates are Punished. Journal of Industrial and Intelligent Information, 3, 197-204.

[7] Demir, H.I., Uygun, O., Cil, I., Ipek, M., \& Sari, M. (2015). Process Planning and Scheduling with SLK Due-Date Assignment where Earliness, Tardiness and Due-Dates are Punished. Journal of Industrial and Intelligent Information, 3, 173-180.

[8] Zhu, C. (2012). Applying Genetic Local Search Algorithm to Solve the Job-Shop Scheduling Problem. International Journal of Industrial Engineering: Theory, Applications and Practice, 19.

[9] Wang, W., \& Li, T. (2011). Improved cultural algorithms for job shop scheduling problem. International Journal of Industrial Engineering: Theory, Applications and Practice, 18.

[10] Nasr, N., \& Elsayed, E. (1990). A. Job shop scheduling with alternative machines. International Journal of Production Research, 28, 1595-1609.

[11] Hutchison, J., Leong, K., Snyder, D., \& Ward, P. (1991). Scheduling approaches for random job shop flexible manufacturing systems. International Journal of Production Research, 29, 1053-1067.

[12] Chen, Q.M., \& Khoshnevis, B. (1993). Scheduling with flexible process plans. Production Planning \& Control, 4, 333-343.

[13] Brandimarte, P. (1999). Exploiting process plan flexibility in production scheduling: A multiobjective approach. European Journal of Operational Research, 114, 59-71.

[14] Morad, N., \& Zalzala, A. (1999). Genetic algorithms in integrated process planning and scheduling. Journal of Intelligent Manufacturing, 10, 169-179.

[15] Ming, X.G., \& Mak, K.L. (2000). A hybrid Hopfield network-genetic algorithm approach to optimal process plan selection. International Journal of Production Research, 38, 1823-1839.

[16] Tan, W., \& Khoshnevis, B. (2000). Integration of process planning and scheduling - a review. Journal of Intelligent Manufacturing, 11, 51-63.

[17] Kim, Y.K., Park, K., \& Ko, J. (2003). A symbiotic evolutionary algorithm for the integration of process planning and job shop scheduling. Computers \& Operations Research, 30, 1151-1171.

[18] Kumar, M., \& Rajotia, S. (2003). Integration of scheduling with computer aided process planning. Journal of Materials Processing Technology, 138, 297-300.

[19] Lim, M.K., \& Zhang, D.Z. (2004). An integrated agent-based approach for responsive control of manufacturing resources. Computers \& Industrial Engineering, 46, 221-232.

[20] Tan, W., \& Khoshnevis, B. (2004). A linearized polynomial mixed integer programming model for the integration of process planning and scheduling. Journal of Intelligent Manufacturing, 15, 593-605.

[21] Kumar, M., \& Rajotia, S. (2005). Integration of process planning and scheduling in a job shop environment. The International Journal of Advanced Manufacturing Technology, 28, 109-116.

[22] Moon, C., Lee, Y.H., Jeong, C.S., \& Yun, Y. (2008). Integrated process planning and scheduling in a supply chain. Computers \& Industrial Engineering, 54, 1048-1061.

[23] Guo, Y.W., Li, W.D., Mileham, A.R., \& Owen, G. W. (2009). Applications of particle swarm optimization in integrated process planning and scheduling. Robotics and Computer-Integrated Manufacturing, 25, 280-288.

[24] Leung, C.W., Wong, T.N., Mak, K.L., \& Fung, R.Y.K. (2010). Integrated process planning and scheduling by an agent-based ant colony optimization. Computers \& Industrial Engineering, $59,166-180$

[25] Phanden, R.K., Jain, A., \& Verma, R. (2011). Integration of process planning and scheduling: a state of the art review. International Journal of Computer Integrated Manufacturing, 24, 517-534.

[26] Petrović, M., Vuković, N., Mitić, M., \& Miljković, Z. (2016). Integration of process planning and scheduling using chaotic particle swarm optimization algorithm. Expert Systems with Applications, 64, 569-588.

[27] Zhang, Z., Tang, R., Peng, T., Tao, L., \& Jia, S. (2016). A method for minimizing the energy consumption of machining system: integration of process planning and scheduling. Journal of Cleaner Production, 137, 1647-1662.

[28] Zhang, L., \& Wong, T.N. (2016). Solving integrated process planning and scheduling problem with 
constructive meta-heuristics. Information Sciences, 340-341, 1-16.

[29] Panwalkar, S.S., Smith, M.L., \& Seidmann, A. (1982). Common Due Date Assignment to Minimize Total Penalty for the One Machine Scheduling Problem. Operations Research, 30, 391-399.

[30] Biskup, D., \& Jahnke, H. (2001). Common due date assignment for scheduling on a single machine with jointly reducible processing times. International Journal of Production Economics, 69, 317-322.

[31] Cheng, T.C.E., Chen, Z.L., \& Shakhlevich, N.V. (2002). Common due date assignment and scheduling with ready times. Computers \& Operations Research, 29, 1957-1967.

[32] Cheng, T.C.E., Kang, L.Y., \& Ng, C.T. (2005). Single machine due-date scheduling of jobs with decreasing start-time dependent processing times. International Transactions in Operational Research, 12, 355-366.

[33] Lin, S.W., Chou, S.Y., \& Chen, S.C. (2006). Metaheuristic approaches for minimizing total earliness and tardiness penalties of single-machine scheduling with a common due date. Journal of Heuristics, 13, 151-165.

[34] Ying, K.C. (2008). Minimizing earliness-tardiness penalties for common due date single-machine scheduling problems by a recovering beam search algorithm. Computers \& Industrial Engineering, 55, 494-502.

[35] Xia, Y., Chen, B., \& Yue, J. (2008). Job sequencing and due date assignment in a single machine shop with uncertain processing times. European Journal of Operational Research, 184, 63-75.

[36] Gordon, V.S., \& Strusevich, V.A. (2009). Single machine scheduling and due date assignment with positionally dependent processing times. European Journal of Operational Research, 198, 57-62.

[37] Li, J., Yuan, X., Lee, E.S., \& Xu, D. (2011a). Setting due dates to minimize the total weighted possibilistic mean value of the weighted earlinesstardiness costs on a single machine. Computers \& Mathematics with Applications, 62, 4126-4139.

[38] Adamopoulos, G.I., \& Pappis, C.P. (1998). Scheduling under a common due-data on parallel unrelated machines. European Journal of Operational Research, 105, 494-501.

[39] Cheng, T.C.E., \& Kovalyov, M.Y. (1999). Complexity of parallel machine scheduling with processing-plus-wait due dates to minimize maximum absolute lateness. European Journal of Operational Research, 114, 403-410.

[40] Birman, M., \& Mosheiov, G. (2004). A note on a due-date assignment on a two-machine flow-shop. Computers \& Operations Research, 31, 473-480.

[41] Lauff, V., \& Werner, F. (2004). Scheduling with common due date, earliness and tardiness penalties for multimachine problems: A survey. Mathematical and Computer Modelling, 40, 637655.

[42] Allaoua, H., \& Osmane, I. (2010). Variable Parameters Lengths Genetic Algorithm for Minimizing Earliness-Tardiness Penalties of Single Machine Scheduling With a Common Due Date. Electronic Notes in Discrete Mathematics, 36, 471478.

[43] Yang, S.J., Yang, D.L., \& Cheng, T.C.E. (2010). Single-machine due-window assignment and scheduling with job-dependent aging effects and deteriorating maintenance. Computers \& Operations Research, 37, 1510-1514.

[44] Huynh Tuong, N., \& Soukhal, A. (2010). Due dates assignment and JIT scheduling with equal-size jobs. European Journal of Operational Research, 205, 280-289.

[45] Li, X., Gao, L., Zhang, C., \& Shao, X. (2010). A review on Integrated Process Planning and Scheduling. International Journal of Manufacturing Research, 5, 161-180.

[46] Vinod, V., \& Sridharan, R. (2011). Simulation modeling and analysis of due-date assignment methods and scheduling decision rules in a dynamic job shop production system. International Journal of Production Economics, 129, 127-146.

[47] Li, S., Ng, C.T., \& Yuan, J. (2011b). Group scheduling and due date assignment on a single machine. International Journal of Production Economics, 130, 230-235.

[48] Zhang, R., \& Wu, C. (2012). A hybrid local search algorithm for scheduling real-world job shops with batch-wise pending due dates. Engineering Applications of Artificial Intelligence, 25, 209-221.

[49] Yin, Y., Cheng, S.R., Cheng, T.C.E., Wu, C.C., \& Wu, W.H. (2012). Two-agent single-machine scheduling with assignable due dates. Applied Mathematics and Computation, 219, 1674-1685.

[50] Iranpoor, M., Fatemi Ghomi, S.M.T., \& Zandieh, M. (2013). Due-date assignment and machine scheduling in a low machine-rate situation with stochastic processing times. Computers \& Operations Research, 40, 1100-1108.

[51] Yin, Y., Cheng, T.C.E., Cheng, S.R., \& Wu, C.C. (2013). Single-machine batch delivery scheduling with an assignable common due date and controllable processing times. Computers \& Industrial Engineering, 65, 652-662.

[52] Shabtay, D. (2016). Optimal restricted due date assignment in scheduling. European Journal of Operational Research, 252, 79-89.

[53] Koulamas, C. (2017). Common due date assignment with generalized earliness / tardiness penalties. Computers \& Industrial Engineering, 109, 79-83. 
[54] Mosheiov, G., \& Sarig, A. (2010). Scheduling with a common due-window: Polynomially solvable cases. Information Sciences, 180, 1492-1505.

[55] Cheng, T.C.E., Yang, S.J., \& Yang, D.L. (2012). Common due-window assignment and scheduling of linear time-dependent deteriorating jobs and a deteriorating maintenance activity. International Journal of Production Economics, 135, 154-161.

[56] Zhao, C., \& Tang, H. (2012). A note to due-window assignment and single machine scheduling with deteriorating jobs and a rate-modifying activity. Computers \& Operations Research, 39, 1300-1303.

[57] Janiak, A., Janiak, W., Kovalyov, M.Y., Kozan, E., $\&$ Pesch, E. (2013). Parallel machine scheduling and common due window assignment with job independent earliness and tardiness costs. Information Sciences, 224, 109-117.

[58] Wang, J.B., Liu, L., \& Wang, C. (2013). Single machine SLK/DIF due window assignment problem with learning effect and deteriorating jobs. Applied Mathematical Modelling, 37, 8394-8400.

[59] Ji, M., Ge, J., Chen, K., \& Cheng, T.C.E. (2013). Single-machine due-window assignment and scheduling with resource allocation, aging effect, and a deteriorating rate-modifying activity. Computers \& Industrial Engineering, 66, 952-961.

[60] Ji, M., Chen, K., Ge, J., \& Cheng, T.C.E. (2014). Group scheduling and job-dependent due window assignment based on a common flow allowance. Computers \& Industrial Engineering, 68, 35-41.

[61] Yang, D.L., Lai, C.J., \& Yang, S.J. (2014). Scheduling problems with multiple due windows assignment and controllable processing times on a single machine. International Journal of Production Economics, 150, 96-103.

[62] Liu, L., Wang, J.J. , Liu, F., \& Liu, M. (2017). Single machine due window assignment and resource allocation scheduling problems with learning and general positional effects. Journal of Manufacturing Systems, 43, Part 1, 1-14.

[63] Rechenberg, I. (1965). Cybernetic Solution Path of an Experimental Problem. Ministry of Aviation, Royal Aircraft Establishment Library Translation No: 1122.

[64] Schwefel, H.P. (1981). Numerical Optimization of Computer Models. John Wiley \& Sons, Inc.: New York, NY.

Halil Ibrahim Demir was born in Sivas, Turkey in 1971. In 1988 he received a full scholarship and entered Bilkent University, Ankara, Turkey, to study in the Industrial Engineering Department. He got his Bachelor of Science degree in Industrial Engineering in 1993. In 1994, he received a full scholarship for graduate study in the USA from the Ministry of Education of Turkey. In 1997 he received a Master of Science degree in Industrial Engineering from Lehigh University, Bethlehem, Pennsylvania, USA. He was then accepted to Northeastern University, Boston, Massachusetts for Ph.D. study. He finished his Ph.D. courses at Northeastern and completed a Ph.D. thesis at Sakarya University, Turkey in 2005 for a Ph.D. in Industrial Engineering. He obtained an academic position at Sakarya University as an Assistant Professor. His Research Areas are Production Planning, Scheduling, Application of OR, Simulation, Artificial intelligence techniques, Genetic algorithms, Artificial Neural Networks, Fuzzy Logic and Decision making.

Onur Canpolat was born in Elazı̆̆, Turkey in 1990. He is currently a Research Assistant in the Department of Industrial Engineering at Sakarya University, Sakarya, Turkey. He received BSc. and MSc. degree in Industrial Engineering from Sakarya University, Sakarya, Turkey in 2012 and 2016, respectively. He is currently a PhD student at the same university. His areas of interest include multi-criteria decision making, operations research and optimization.

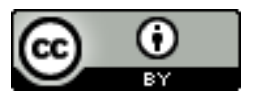

This work is licensed under a Creative Commons Attribution 4.0 International License. The authors retain ownership of the copyright for their article, but they allow anyone to download, reuse, reprint, modify, distribute, and/or copy articles in IJOCTA, so long as the original authors and source are credited. To see the complete license contents, please visit http://creativecommons.org/licenses/by/4.0/. 